\title{
Bolivia and the Vicuña
}

\author{
$H$. Jungius
}

In pre-Columbian times vicuñas ranged in their hundreds of thousands in Argentina, Chile, Peru, Bolivia and Ecuador; the Incas harvested their valuable wool by rounding them up and shearing them. Today a mere remnant survives, almost entirely in Peru and Bolivia. Urged by conservationists, notably Sr Felipe Benavides, FPS Vice-president and WWF Trustee, Peru and, later, Bolivia have taken steps to save the vicuña by prohibiting the export of the wool, and creating reserves; last year, in response to their request, the British Government banned all imports of vicuna wool, a move in which the FPS played a considerable part (see Oryx, December 1970, page 343). In $1969 \mathrm{Dr}$. Jungius with another biologist was sent by UNESCO, following a request for advice and help from the Bolivian Government; in 1971 he went out a second time, supported by the Frankfurt Zoological Society and WWF. In this article he describes the vicuña situation, some of the difficulties in protecting the vicuña, and some of his recommendations, including a method of enabling wild vicuña and domestic alpaca to utilise the same area.

The vicuna is one of the last wild representatives of the camel family. Only two others survive: the guanaco, also in South America, and the two-humped camel in the Gobi desert of Mongolia. All other members of the family, including the llama and the alpaca in South America, exist only in the domestic state.

The camels originated and developed in North America (as did the horse, in the Tertiary Age), whence some migrated to South America, Asia, Europe and North Africa. The North American representatives, the Camelops and Tanupolama, became extinct in the Pleistocene at about 8000-8500 B.C., probably as a result of climatic changes bringing more extreme seasonal contrasts. In South America in the Pleistocene the range of the vicuna extended into the lowlands as far east as Buenos Aires; its present range in the central Andes (between $3500-4800$ metres) therefore represents only a very selected habitat where it managed to survive due to particular adaptation. But despite the remoteness of its habitat this gazelle-like ungulate is more threatened with extermination to-day than ever before.

Vicuna wool and skins are highly prized in Europe and in North America and also by westernised tourists. The wool is used to make fine textiles, and the tourist buys scarves, jumpers, stoles and 'colchas' (blankets made from skins) as souvenirs, not knowing, often not caring, that thousands of animals have to be slaughtered to produce them. Each vicuna produces 120 grams of fine wool (Herre 1963), to obtain which it is shot; the animals are not sheared, as sheep and alpacas are, because they are not kept in domestic herds. It takes three vicunas to Dr Jungius is Conservation Officer with the World Wildlife Fund in Switzerland. 
knit a jumper, one to produce a scarf. In a colcha you can find pieces taken from 150 to 250 animals, often from lambs, whose wool is extremely soft up to the age of three months. In a typical souvenir shop in La Paz, capital of Bolivia, I found one colcha produced from the heads of 168 animals and another made out of the necks of 60 lambs.

Thus the demand for luxury goods from highly developed countries destroys a natural resource in developing countries, which, properly managed, could produce considerable revenue.

The vicuna has never become domesticated, unlike the guanaco, from which the llama and the alpaca originated*. Long before the Inca Empire the llama was used as a beast of burden and the alpaca was bred for its wool. The Incas, however, exploited the vicuña intensively for centuries, systematically harvesting the fleece and the wool (and, according to some authors, the meat as well), and so making the vicuna probably the most important wild South American mammal of precolumbian times. Their method, described by several authors (Cardozo 1954, Koford 1957), was to round up and shear the animals once every three or five years; a few were killed for meat and for the skins, but the majority were released again. Only the Inca (and certain priests) were allowed to wear vicuna cloth, and it is reported that the Inca wore his clothes for only one day, after which they were burned. Vicuna wool was thus valuable and in continuous demand. The laws were strict, and Inca officials made sure that there was no illegal hunting.

The Andean Indians believed that the vicuna was the daughter of Pachamama, the goddess of fertility, and therefore sacred, so the vicuna were not harmed - I found that this belief is still held among Aymara Indians in some remote valleys. But after the Spanish conquest the old laws and beliefs were no longer respected by either the conquerors or most of the Indians, and there was uncontrolled hunting. Sixteenthcentury reports tell of 80,000 animals being killed each year.

\section{Present Status}

The vicuna is found in the high Andes, in places between 3500 and 4800 metres where there is sufficient pasture and water. In summer they go higher and stay close to the snowline. About 150 years ago vicunas were common in middle Chile, the northern provinces of Argentina, the Bolivian Andes, the Peruvian highlands, and southern Ecuador. Today they are extinct in Ecuador, but the other four countries still claim to have wild vicunas.

Argentina In 1957 the Herre/Röhrs South American Expedition was able to confirm that there were vicunas in the Cachima mountains and near La Quiaca on the Argentine/Bolivian frontier. Röhrs (1957) assumed that vicunas occurred in the northern provinces of Salta and Jujuy. Today, according to Mr. W. Everts, who returned in 1970 from a one-year zoological expedition to Argentina, small groups may have *Earlier statements that the alpaca derives from the vicuna and that the guanaco is only the ancestor of the llama have been disputed, and recent investigations by Herre $(1952,1953)$ and others (Fallet, 1961) from Kiel University, Germany, have confirmed the views of other great mammalogists like Heck, Klatt, Lönnberg and Trouessart that alpaca and llama derive from the guanaco and that the vicufia was never domesticated. 


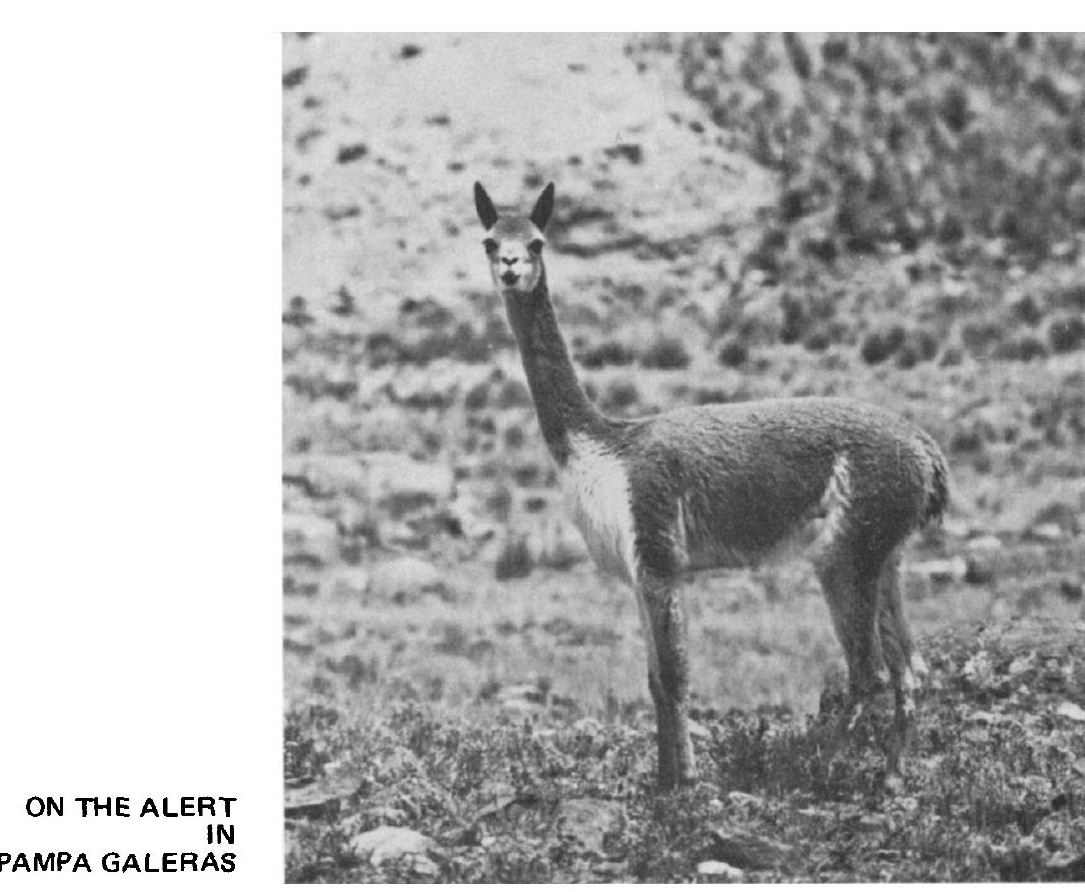

survived in remote areas of the northern cordillera, but no sightings were made and no definitive data obtained, despite a thorough survey of the area and enquiries among local people. Probably the vicuna has been exterminated in Argentina.

Chile The vicuna has been exterminated in middle Chile, but small groups are believed to survive along the northern frontier with Bolivia in the latitude of Sabaya-Sajama (Cordier). Mr. Rottmann and Mr. Stutzin, of the National Committee for the Protection of Fauna and Flora, told me that a minimum of 200 to 400 exist in the Lauca valley (Tarapaca province) where a new national park, the Rio Lauca, has been established recently, at least 200 in the Antofagasta province, and not more than 50 in the Atacama province. These are very rough estimates but more precise data are expected soon.

Peru From Grimwood's survey (1969) and personal consultations with C.Ponce and R.Hofmann it is clear that there are at least 10,000 vicuñas in Peru, about 5,000 of them in the Pampa Galeras reserve where they are well protected, and numbers are increasing. There are plans to catch animals in populated areas for reintroduction in the country surrounding the reserve. After visiting Pampa Galeras I can state that the Peruvian authorities have done an excellent job, and that funds provided by the Belgian Government and the Frankfurt Zoological Society for equipment and for wardens' houses have been well used. Bolivia There was no recent data from Bolivia when I started my studies there in 1969, but I can now clarify the picture (Jungius 1971).

There are two centres of vicuna concentration in the altiplano. One is around the village of Ulla Ulla (4327 m.), 60 kilometres north-east of Lake Titicaca near the Peruvian frontier, and the other south-west of the lake, around Santiago de Machaca. In the first there are about 220 animals, and in the other about 100 . There are also several small groups around Lake Poopo, and 100 to 150 scattered in small groups of three 
to ten individuals, in the dry regions of the southern altiplano. In this area young vicuna were rarely seen, and several of these small populations are probably near to extermination.

In the eastern Cordillera the vicuna has been exterminated in most of its previous habitats. There is a small population north of Cochabamba and in several. remote valleys (for instance in the Cordillera de los Frailes west of Potosi) similar remnant populations can be expected. Including other scattered populations of 10 to 40 animals north-west of Lake Poopo and around the farm of 'Eucalyptus' east of Oruro, it can reasonably be assumed that an overall population of 1000 vicunas has managed to evade the indiscriminate hunter.

\section{The Present Situation in Bolivia}

Except in the region around Ulla Ulla (see below) the vicuna is being rapidly exterminated all over Bolivia due to increased hunting pressure and to competition for habitat from alpaca and in some places llamas and sheep. The vicuna has been displaced from most good grazing sites, and small populations manage to survive only in habitats that are less attractive to livestock and difficult of access. These are in dry parts of the southern altiplano in the provinces of Nor and Sud Lipez, including the rims of large and small saltpans, and in the flat gravel plains where sparse vegetation peters out into pure salt desert. Other zones of retreat exist in the eastern Cordillera (see above). In several of these areas small but socially healthy vicuna groups still reproduce regularly. However, they are subjected to enormous hunting pressure, despite legal protection, and a crash in their numbers is forseeable in the next few years. The lack of game wardens and the local authorities' poor facilities mean that poachers rarely get caught, accused or fined. These vicuna could be saved if existing laws were enforced; with proper game management techniques their numbers could be increased to the levels at which scientifically controlled cropping schemes on a profitable sustained-yield basis could be permitted.

Bolivia took the first steps towards active protection and the rebuilding of depleted vicuna stocks in 1969, when the Government asked UNESCO for technical help and advice on how to set up management plans for national parks and where to establish appropriate reserves. As a result two biologists, $R$. Pujol and myself, were sent to Bolivia. In co-operation with the local authorities, I started a survey on the altiplano with the objective of recommending the establishment of Bolivia's first vicuna reserve, and, after careful consideration and discussion with the Department for Wildlife and National Parks, we recommended that a reserve be established around Ulla Ulla, in the province of $\mathrm{La} \mathrm{Paz}$, where a population of 150 vicuñas (1969) had survived the slaughter of previous years. The area is one of outstanding beauty, which is fairly rare in the monotonous altiplano, and is inhabited also by numerous typical representatives of the high-Andean fauna and flora (see below). Two wardens were sent there, established their headquarters at Ulla Ulla, and started patrolling immediately. Most of their work has to be done on foot, but despite their limited facilities and lack of assistance they have managed to stop any further 


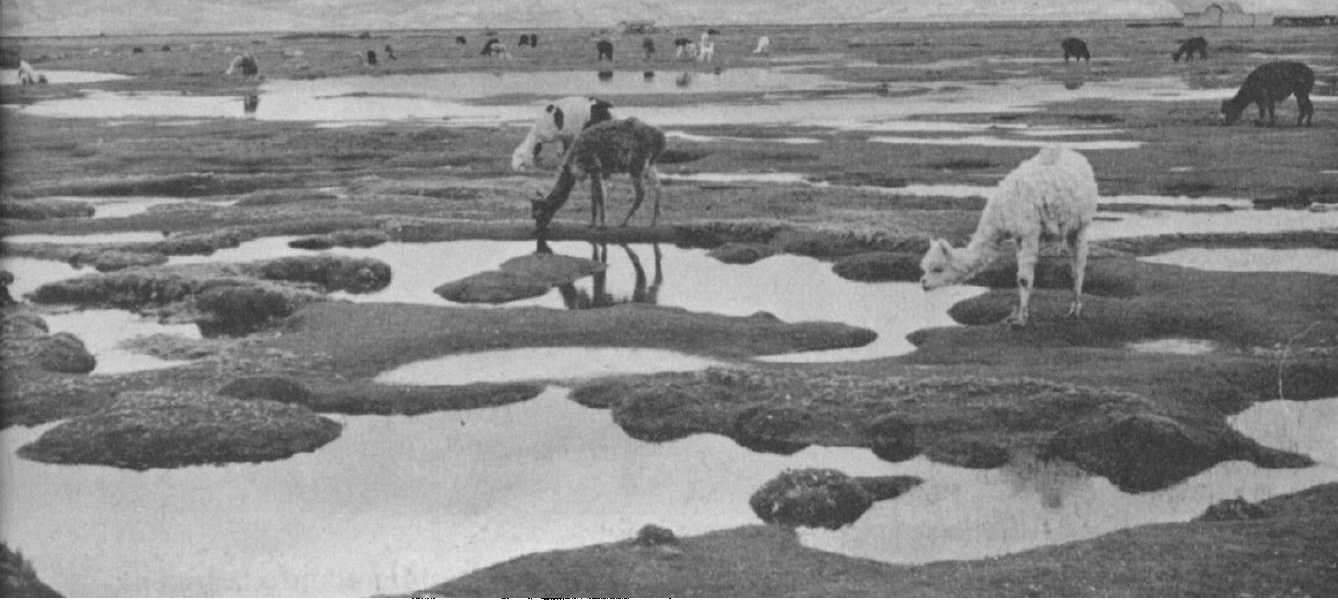

ALPACAS grazing in the bofedal in Ulla Ulla

decline in the vicunas. Poaching has been largely prevented, and by 1971 numbers, estimated at 200 to 220 , were again on an upward trend.

The area, which is officially called Reserva National de Fauna Ulla Ulla was proclaimed a National Reserve on January 7, 1972. The lowest point of the reserve is at $4327 \mathrm{~m}$, and it covers about 100,000 ha. on the eastern side of the Andes, and another 100,000 ha. on the western side which is where the vicuna are found. In the centre is the pampa of Ulla Ulla, one of the highest puna* areas in Bolivia, bordered on the east by a most impressive mountain chain of snow-covered peaks approaching $6000 \mathrm{~m}$ and glaciers. Westwards from the foot of this mountain chain, in an extensive moraine-zone created by former glaciers, there are several glacier lakes, of which Lago Suches, $20 \mathrm{~km}$ long, is the largest in Bolivia. From the foothills the land becomes a dry gravel plain sloping slightly to the west and merging into the central pampa, which also slopes gently. Glacier tongues in the tropics are continuously melting, so rivers fed by glacier lakes supply the lower part of the pampa with water all the year round. In summer and autumn (during and after the rain) and also to a lesser extent in winter this is a fairly wide flood plain with many small, slow running watercourses and numerous pools. For most of the year it is covered by luxurious vegetation, and in the centre is a typical high mountain peat bog, or 'bofedal', where there is permanent and stagnant water throughout the year and where the hard cushions of Distichia muscoides and lawns of Alchemilla pinnata dominate. This bofedal is excellent vicuna habitat and could support thousands, but no vicuna graze there because the whole area is densely occupied by alpacas, making it impossible for the vicuña to enter.

*Flat or rolling country in the high Andes. Dry puna has an annual rainfall below $400 \mathrm{~mm}$; moist puna has between $400-1000 \mathrm{~mm}$. The typical vegetation is bunch grasses, tola shrub, cushion plants. 


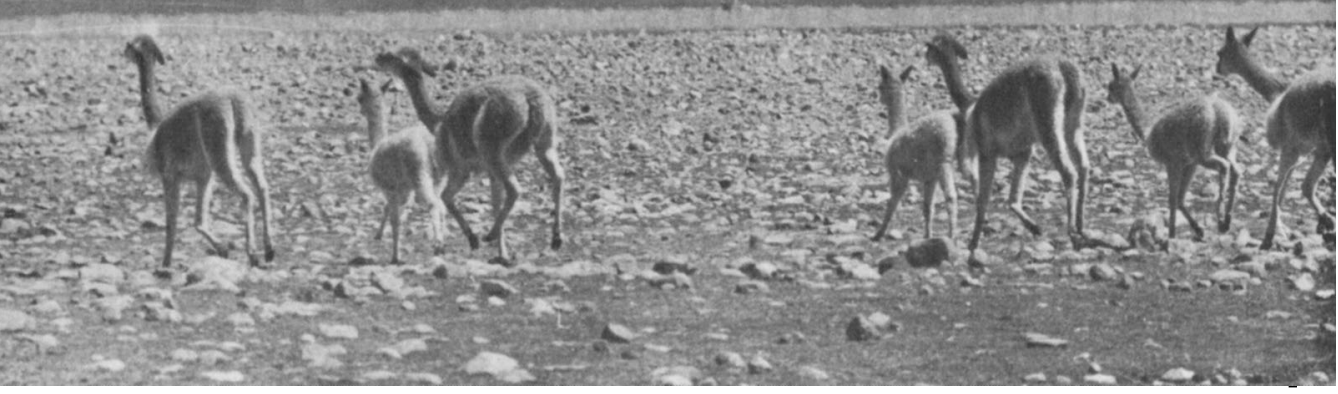

Family with three-months'-old lambs

Vicuna and alpaca compete for space and pasture and do not easily associate. Both need water every day and prefer vegetation with a high moisture content. The most favourable pastures in the region are in the bofedal and alongside the rivers which form wide shallow beds with small flood plains. Between these grazing sites are dry slopes with sparse vegetation which are of little grazing value for livestock and are thus normally avoided or only traversed occasionally by alpacas on their way to the good pasture by the rivers. The severe competition of alpaca and the hostility of many herdsmen, who regard the vicuna as a competitor, prevent the vicunas from entering the bofedal and force them to use the dry gravel plains. Alpaca herds, therefore, are the major problem to be overcome in the planning for this reserve. It is impossible to move them and their owners from their favourite feeding grounds, so other means must be found to protect and increase the small vicuna stocks.

Management schemes, therefore, must take into consideration the education of the public, particularly local inhabitants, to see the advantages of scientifically based conservation and management programmes and the economic utilisation of the vicuña for their benefit as well as further research, etc. Biological investigations will have to include (see Jungius 1971) the behavioural patterns of both vicuna and domestic stock, especially alpaca, the ways in which they interact and their different utilisation of the habitat.

\section{Different Behaviour Patterns}

Alpacas form loose associations of 50 to several hundred individuals, and a grouping pattern which is an open social community, in which individuals are free to leave or join whenever they like. They are normally driven to their grazing grounds, but are sometimes also left to themselves. In the evenings they return to their resting corrals or may be herded there by their owners. Their grazing pressure on the bofedal is very heavy, and they are commonly to be seen crowded together on their favourite sites. When they are on the move they also feed on the humid vegetation beside the rivers. 


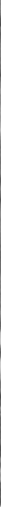

Family including a pregnant female

In the rainy season (December-March) and in April and May, they also graze on the fresh vegetation shoots on the edges of the bofedal, and because these are less luxuriant than in the bofedal they spread out and graze a wider area. But with the dry-season decline in the food value of the grazing they withdraw more and more into the bofedal which then becomes heavily encroached and overgrazed, leading in dry years to habitat destruction and starvation for hundreds of alpacas (Nogales pers. com.). The bofedal is thus the alpacas' main winter grazing area, and the Indians do everything they can to prevent it drying up. Dams are built to prevent run-off, pools created, and ditches dug to inundate additional areas to create a Distichia muscoides community.

Vicuna have three main social forms: family parties, bachelor troops, and solitary males which try to establish a territory and dominate females - I observed this in spring as well as in autumn. (Koford 1957, Röhrs 1957.) The family parties consist of one male, several females (I have counted up to twelve), and young ones, with the male the dominant and leading individual. He establishes a territory which he defends against intruding males, and occupies it for months or even years, the size depending on the availability of food and water. One vicuña needs between four and fifty hectares; in semi-deserts even more (Koford 1957, own observation). Normally they establish territories beside the rivers, but they are also found away from rivers, which means that they have to go daily to watering places. But because the moist riverside stretches are only a few metres wide or even absent altogether, there is insufficient food, and the vicuña are forced to utilise the adjacent dry area where the vegetation is scanty; in these areas it is normal to see members of a family grazing at considerable distances from each other. On the other hand they have little competition here. The few herbivorous rodents and llamas are not an important limiting factor for the vicuna.

The bachelor troops are formed by young males (yearlings) which 
have to leave the family parties (when the young are born) and the adult males that failed to found a territory and dominate a female. These troops seem not to have a social order or leadership; they do not occupy territories and therefore are not attached to one place, but graze vast areas, their 'home ranges'. They prefer to graze riverine zones and the edges of the bofedal, but the grazing pressure on alpacas and the hostility of the territorial vicuna males usually force them into the drier, less attractive land.

When all these factors are taken into account it is clear that the chances of attracting vicunas to the bofedal are small. At Ulla Ulla there is little hope of attracting the territorial family parties into the bofedal while it is disturbed by thousands of alpacas. But the free-roaming bachelor troops are different, and if hunting and attacks by dogs could be stopped, they could be attracted, particularly in the rainy season when the alpacas are widely spaced; they would have to move out again in winter, when the alpacas concentrate in the bofedal. Another important consideration is that vicunas belong to those ungulates which do not associate freely with other animals. Whether grazing or resting they maintain well defined distances from other species, varying from 50 to 300 metres in the case of alpaca, which is usually sufficient to prevent them grazing on good pasture where alpacas are grazing. The narrow riverside strips are sometimes only 10 metres wide, and the bofedal often changes abruptly into drier zones. However, there is wide variation in the distance which vicunas keep from alpacas, and if means could be found to reduce this distance the vicunas could get the enormous advantage of the better grazing sites.

During my investigations $I$ discovered that the distance the vicunas maintain from either stock or people is largely influenced by experience. The presence of alpacas implies herdsmen and dogs, and where vicufia had been regularly chased by dogs the distance they maintained was much greater than in undisturbed areas. I was able to confirm this in Ulla Ulla last year. In the area around the village, where permanent patrols of gamekeepers prevented molestation and poaching, the vicunas became much less wary and stayed nearer the alpacas. A family party of seven vicuña were often observed grazing close to one of the small Aymara settlements in the central pampa, and the Indians of this village were particularly proud about this and prevented them being disturbed whenever possible. Thus, by strict protection and by destroying all uncontrolled dogs, it may be possible to encourage vicunas to extend their range to the outskirts of the bofedal and even to penetrate temporarily but regularly into it.

To sum up: The bofedal is and will remain the important grazing area for alpacas and so can only be used by vicunas to a very small extent. Careful management techniques could encourage vicunas to frequent the outskirts of the bofedal and bachelor troops to enter it during the wet season. It follows that the main conservation work for increasing vicuna stocks must be concentrated on the dry gravel plains. This is possible, because the species is well adapted to survive on poor vegetation. By preventing alpacas from moving uncontrolled through these areas, avoiding temporary concentrations of alpacas in places 


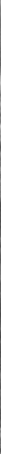

Part of a bachelor troop of 95 vicuña in Pampa Galeras

frequented by vicunas, and putting a stop to poaching and chasing by dogs, conditions for the vicuna could be considerably improved. Moreover, these are the right conditions for demonstrating a new conservation concept already practised successfully in North America, and Africa, which is to run livestock and wild animals together without imposing severe limitations on the stockbreeders. Under careful management it should be possible to establish a system whereby the domestic alpaca use the favourite pasture but the wild vicuna also have access at times when food is abundant, being at other times restricted to the edges of the zone which are unsuitable for domestic stock. In this way a healthy coexistence could be established which in the end would greatly benefit the local inhabitants; moreover, the whole spectrum of the biotope would be utilised.

In addition to management along these lines, it is planned to start a well protected and managed vicuna propagation centre using modern field management techniques to improve grazing and water facilities. This would be in an area closed to livestock, where the vicuña would be undisturbed and from where they could migrate and repopulate the surrounding regions. The proposal is to proclaim about 10,000 ha of the dry zone as a strict reserve, from which all livestock would be excluded and where the movement of domestic animals through the area is controlled. This idea is not new, having first been tried in Pampa Galeras, in Peru, where similar arrangements were made with the local communities of Indians. To make the idea attractive to the herdsmen a government veterinary station is proposed in Ulla Ulla with a permanent vet in charge. The usual bait of tourism, a long-term benefit here, will be applicable only after patient development.

The Ulla Ulla reserve, the first Bolivian vicuña reserve, is unique, and enhanced by the outstandingly beautiful scenery and the diversity of its wildlife. Because it is a less favourable habitat Ulla Ulla will never support as many vicuna as does Pampa Galeras, where there are 5000, 
but it will provide a greater variety of High Andean wildlife. In the eastern part are Andean deer Hippocamelus antisiensis and possibly also the spectacled bear Tremarctos omatus. Among predators the Andean fox Dusicyon culpaeus is very common. Two wild cat species have been seen, one a Lynchailurus, and there is one skunk Conepatus rex. Rodents are particularly numerous, with five or six species of leaf-eared mice Phyllotis species, mountain viscacha Lagidium species, Ctenomys, Acodon, Galea and others. Condors are regularly seen and quickly attracted by dead stock, the Andean caracara occurs everywhere, the Andean lapwing or leke leke is common, and the giant coot nests on most of the lakes where ducks regularly seen include Anas flavirostris oxypterum, A. puna, Lophonetta specularioides alticola, Anas georgica spinicauda, Oxyura jamaicensis ferruginea. The first four species are also seen in large numbers on the ponds of the bofedal, but Oxyura occurs only on the lakes. The Andean gull Larus serranus, night heron Nycticorax nycticorax, two grebes Podiceps rolland and Podiceps occipitalis, and large flocks of the Andean goose and the Andean glossy ibis are a common sight in the bofedal and on the lakes. There are also finches, tyrants, and earth creepers, and in steep river banks or in old walls the Andean flicker Colaptes rupicola, the only representative of its family that lives in a treeless country, makes its nest holes. Even amphibians and reptiles are found at this altitude, and a lizard Liolaemus multiformis can be found up to 4800 metres.

\section{The Outlook}

At present the Ulla Ulla reserve is controlled by one senior warden and two game guards, all trained on a game wardens' course in Peru, and two assistants. Their equipment and their headquarters were provided by the Frankfurt Zoological Society in 1971. The Ministry of Agriculture has promised to increase the number of guards in order to control the eastern side of the reserve more effectively. Following discussions with Peru it is now proposed to make this a bi-national reserve by making a reserve on the Peruvian side of the frontier adjoining the protected area in Bolivia. (Another bi-national conservation unit in South America is the area of the Iguazu waterfalls on the Brazil-Argentine frontier.) The World Wildlife Fund has given top priority to the request for financial assistance for equipment and wardens' accommodation.

It must be emphasised that one of the most important factors for the survival and increase of the depleted vicuna stocks is the establishment of further reserves or controlled areas with sufficient game wardens to guard them and prevent poaching. Once a substantial population is obtained, a planned reintroduction scheme can be started to repopulate the former range. In Bolivia I repeatedly passed through excellent vicuña habitats where the species has been wiped out and where domestic stock also is rare. Regions which once sustained an immense amount of wildlife are now mostly without it. Bolivia is making a great effort to develop its natural resources in the lowlands, but the altiplano also has resources that are potentially of great economic, educational and cultural value. Once re-established, vicunas could be used commercially, their wool sheared, and meat and skins 
obtained by controlled cropping in the bachelor troops. This needs strict government control and properly developed management plans. In Peru a wildlife expert Dr. R. Hofmann is now working in this field.

Because it is not possible to exclude men and livestock from the Ulla Ulla reserve, a compromise must be found; field studies must be done to solve the problems of competition, pasture utilisation, and the interaction of alpacas, vicunas and other wildlife.

To create an awareness of the economic value of vicuna, among both government and people, a comprehensive education campaign is essential, with the aim of changing traditional rights and customs that impede vicuna conservation. This will be difficult and needs tactful handling. To poor people the vicuna is nothing but a competitor for their stock and a producer of excellent wool and skins which make a good profit when sold, and they cannot be expected to protect a wild animal for its beauty or for science. The approach can only succeed on economic grounds; only later can the development of tourism and the promotion of cultural and educational values be emphasised.

The World Wildlife Fund realises this, and, in co-operation with the Frankfurt Zoological Society, and the Bolivian and Peruvian governments, a poster and leaflet campaign is in preparation, aimed at schools and the various levels of the public. If successful, this should be followed up by newspaper activities and audio visual aids.

Finally, I should like to emphasise that the vicuña has never been domesticated, despite several attempts in the last hundred years. The latest attempt was on the privately owned hacienda 'Cala Cala' in Peru, the results of which should be a warning to every responsible conservationist. Vicunas were cross-bred with alpacas to produce 'paco-vicunas', whose wool combines the fine quality of the vicuña with the high quantity of the alpaca. Unfortunately, hybrids and pureblooded animals were not kept separate, interbreeding occurred, and hybrids of different generations ran together with pure vicunas and pure alpacas. To make the situation worse, llama were also used for cross-breeding experiments. Of the 800 'vicunas' still on this property a large number are pure, but no one can say which. This area has fortunately not been proclaimed as a national park or reserve, as had been suggested, and the Peruvian government has taken over responsibility. Ministry of Agriculture experts are separating specimens for a selective scientific breeding programme based on modern genetic knowledge. It is essential that none of these animals leaves the property before its genetic composition is clearly known, because if hybrids, which often look like a vicuna, are introduced into small populations of pure vicunas, the results could be disastrous. Alpaca and vicuna can, of course, be successfully interbred provided precautions are taken, but I doubt whether it is possible on a commercial basis, and I feel strongly that the future of vicuna utilisation is not in this field. Its best chance lies in the production of wool, skins and meat under sound game management, with later the attraction of tourism.

The vicuna is still included in the IUCN Red Data Book, but there is reason to hope that it will survive and increase again so that it can be removed. Peru and Bolivia have realised how important it is to start 
active conservation, and Peru has already achieved remarkable results. Bolivia is still trying to get its first reserve on its feet and has the formidable task and responsibility of prohibiting the enormous trade in vicuna articles in its country.

But conservation is under way. International organisations for nature conservation are recognising that South America has had little attention and needs help. The Frankfurt Zoological Society, IUCN, the World Wildlife Fund and the FPS are all backing the growing efforts in Latin American countries to protect and conserve their endangered wildlife.

\section{Acknowledgments}

Thanks are expressed to UNESCO for financing my work in 1969. Grateful acknowledgement is made to the Frankfurt Zoological Society for providing funds to continue my work in the Reserve of Ulla Ulla in 1971. I am very indebted to the World Wildlife Fund for providing the possibility to direct the work in Bolivia in 1971. Thanks are also expressed to Ing. P. Baptista, Chief of the National Parks Division, Ing. W. Terrazas, Chief of the Forestry Department, Dr. A. Cardozo, R. Pujol, C. Cordier, Mr. G. Stutzin and the Game Warden J. Nogales for providing me with much help and information. I am grateful to Mr. J.N. Glass for correcting the manuscript.

\section{References}

CARDOZO, A., 1954: Auquenidos, La Paz.

FALLET, M., 1961: Vergleichende Untersuchungen zur Wollbildung Südamerikanischer Tylopoden. Z. Tierz. Züchtgsbiol. 75: $34-56$.

GRIMWOOD, I. R., 1969: Notes on the distribution and status of some Peruvian mammals. Amer. Com. Int. Wild Life Protection and N.Y. Zool. Soc. Spec. Publ. 21.

HERRE, W. 1952: Studien über die wilden und domestizierten Tylopoden Südamerikas. Zool. Garten N.F. 19: 70-98.

HERRE, W., 1963: Einiges vom Vikuna, dem zierlichen Bergkamel. Freunde des Kolner Zoo, 1, 6. Jahrg.

HERRE, W., 1953: Die Herkunft des Alpaka. Säugetierkundl. Mitteilungen 14: 176-177.

JUNGIUS, H., 1971:32, The vicuna in Bolivia: the status of an endangered species and recommendations for its conservation. Zeitschrift für Säugetierkunde, 36,3: 129-146.

KOFORD, C. B., 1957: The vicuna and the puna. Ecological Monographs, 27,2 .

RÖHRS, M., 1957: Ökologische Beobachtungen an wildlebenden Tylopoden Südamerikas. Verh. Dtsch. Zool. Ges.: 538-554.

\section{Vicuña in Argentina}

As Oryx goes to press Jeffery Boswall, of the BBC Natural History Unit, reports that in March this year he saw vicuñas in Jujuy province in Argentina - about 80 in one locality and about 10 in another. He also has reliable reports of small numbers of vicuña seen in six other places in the province in the last two years, and one record for November 1970 of 20-30 seen in Catamarca province. He concludes that 'the Argentine population can confidently be measured in hundreds of animals'. Details of his report will be given in the next issue of Oryx. 